\title{
IMPLEMENTASI WEIGHTED PRODUCT PENGKLASIFIKASIAN LAHAN PERTANIAN
}

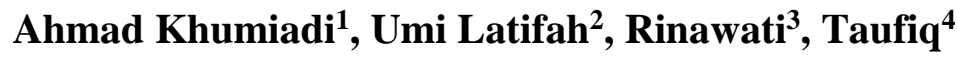 \\ ${ }^{1,2,3,4}$ Prodi Sistem Informasi, STMIK Pringsewu \\ Jalan Wisma Rini No.09 Pringsewu, Lampung, Indonesia \\ ahamdkhumiadi@gmail.com, umilatifah300@gmail.com
}

\begin{abstract}
Abstrak
Untuk kegiatan pertanian memerlukan lahan yang terbaik untuk bercocok tanam, sehingga hasil pangan yang dihasilkan juga berkualitas. Lahan merupakan salah satu komoditi penting yang merupakan mata pencaharian para penduduk Indonesia. Penentuan pengklasifikasian lahan meliputi penilaian kriteria-kriteria suatu daerah. Adapun kriteria-kriteria suatu daerah yaitu jenis lahan, tekstur lahan, curah hujan, suhu, lokasi, dan nilai. Pemanfaatan sistem pendukung keputusan sangat membantu dalam penentuan kelayakan daerah pertanian, dan disertai dengan metode Weighted Product. Dengan adanya sistem pendukung keputusan akan lebih mempermudah penduduk dalam memilih lahan untuk bercocok tanam. Hasil yang dicapai dalam pemanfaatan metode Weighted Product setelah melakukan pembobotan dari empat alternatif yang dipilih terdapat pada alternatif ke empat dengan bobot terbesar, maka alternative ini bisa dijadikan acuan untuk lahan terbaik.
\end{abstract}

Kata Kunci_Weighted Product; klasifikasi Lahan; Sendang Agung;

Abstract

For agricultural activities requires the best land for cultivation, so that the resulting food quality is also qualified. Land is one of the important commodities which is the livelihood of the Indonesian people. Determination of land classification includes assessment of criteria of a region. The criteria of a region that is the type of land, texture of land, rainfall, temperature, location, and value. Utilization of decision support system is very helpful in determining the feasibility of agricultural areas, and is accompanied by Weighted Product method. With the decision support system will further facilitate the population in choosing land for cultivation. The results achieved in the use of the Weighted Product method after the weighting of the four selected alternatives are found in the fourth alternative with the greatest weight, this alternative can be used as a reference for the best land.

Keywords-Weighted Product; Land Classification; Sendang Agung; 


\section{Pendahuluan}

Sebagian besar lahan sawah di Indonesia pada awalnya merupakan hasil perkebunan areal lahan kering. Banyak lahan kering yang semula digunakan untuk hutan maupun perkebunan sekarang ini sudah dimanfaatkan sebagai kawasan persawahan. Badan Pusat Statistik (2010) mencatat bahwa luas lahan pertanian di Indonesia pada tahun 2009 sebesar 6.048.447 ha, luas lahan padi ini meningkat sebesar $6,12 \%$ dari tahun sebelumnya. Dalam budidaya padi sawah, dilakukan proses penggenangan yang dapat menyebabkan perbedaan karakteristik tanah yang terdapat pada lahan sawah dan lahan kering. Moorman (1978) mengemukakan bahwa proses penggenangan menciptakan keadaan reduksi yang dapat merubah ciri-ciri morfologi dan sifat-sifat fisika kimia pada profil tanah asal. Perubahan sifat-sifat tanah yang terjadi pada lahan sawah juga menyebabkan perubahan klasifikasitanah asalnya[1].

Dalam penelitian konservasi lahan merupakan bagian dari upaya pengelolaan lahan secara berkelanjutan.Ungkapan paling sederhana konservasi lahan adalah tindakan penggunaan sebagaimana mestinya, artinya lahan digunakan sesuai dengan kelas kemampuannya dan menghindarkannya dari kerusakan. Menurut Notohadiprawiro (1999), menetapkan penggunaan secara layak berbagai lahan yang terdapat dalam lapangan budidaya pertanian (system pertanian) merupakan langkah pertama yang terpenting dalam melaksanakan konservasi tanah. Hal tersebut sejalan dengan pendapat Foster (1964), yang menyatakan bahwa konservasi lahan pada azasnya adalah melaksanakan tataguna lahan dan menyingkiri penggunaan lahan yang membahayakan, adapun pembuatan teras, pertanaman berjalur, pertanaman menurut kontur, dan praktek konservasi lainnya hanyalah merupakan teknik-teknik pelengkap[2].

Decision Support System digunakan dalam proses pengklasifikasian lahan dimaksudkan agar system yang dibangun dapat di kembangkan dengan menggunakan teknologi karena salah satu bentuk system informasi dengan mengumpulkan data yang mana akan di jadikan bahan pertimbangan seperti jenis tanah, curah hujan, perairan, suhu, dan tekstur tanah[3]. Dalam hal ini sebuah lahan dapat digunakan sesuai dengan kemampuan lahan sehingga para petani dapat menikmati hasil pertanian yang baik.

Dalam system klasifikasi lahan, system ini memberikan gambaran dan cara menentukan lahan yang baik untuk para petani diwilayah sendang agung. Dengan system ini seorang petani tidak perlu bersusah payah lagi menentukan lahan yang berkualitas dengan bentuk lahan yang dimiliki, petani juga dapat menanam tanaman petani yang berkualitas sesuai dengan bektuk lahan dan kemampuannya.

\section{Tinjauan Pustaka}

\section{A. Lahan}

Lahan merupakan sumber daya alam yang sangat penting untuk pengembangan usaha pertanian, kebutuhan lahan pertanian semakin meningkat seiring dengan meningkatnya jumlah penduduk, namun luasan lahan yang sesuai bagi kegiatan di bidang pertanian terbatas. Hal ini menjadi kendala untuk meningkatkan produksi pangan dalam rangka memenuhi kebutuhan pangan penduduk.Masyarakat tani yang tradisional memenuhi kebutuhan pangannya dengan menanam secara tradisional.kegiatan pertanian ini menyebabkan degrasi kesuburan tanah melalui erosi dan penggunaan tanah yang terus menerus. Salah satu cara untuk mengatasi masalah ini adalah dengan cara pengklasifikasian lahan yang sesuai dengan kemampuan lahan [4]

Dinamika spesial terkait penggunaan lahan (land use) pada Daerah Aliran Sungai (DAS) akan berpengaruh terhadap mekanisme DAS dan berpotensi mengganggu keseimbangan daerah aliran sungai. Penggunaan lahan yang tidak sesuai dengan kemampuannya, ditambah tekanan penduduk atas lahan di wilayah DAS tentunya sangat mengancam kelestarian daerah aliran sungai. Hal tersebut tentunya harus diantisipasi untuk memelihara fungsi dan kelestarian DAS, tidak hanya pada saat ini, tetapi juga untuk masa yang akan datang[5]

\section{B. Sistem Pendukung Keputusan}

Turban (2005) Sistem Pendukung Keputusan sebagai sebuah system berbasis computer yang membantu dalam proses pengambilan keputusan. Sebagai sistem informasi berbasis komputer yang adaptif, interaktif, fleksibel, yang secara khusus dikembangkan untuk mendukung solusi dari permasalahan manajemen yang tidak terstruktur untuk meningkatkan kualitas pengambilan keputusan. Dengan demikian dapat ditarik satu definisi tentang SPK yaitu sebuah system berbasis computer yang adaptif, fleksibel, dan interaktif yang digunakan untuk memecahkan masalah-masalah tidak terstruktur sehingga meningkatkan nilai keputusan yang diambil [6].

Kusrini (2007), juga mengemukakan bahwa Sistem Pendukung Keputusan merupakan system informasi yang menyediakan informasi, pemodelan dan pemanipulasi data. Definisi lain Sistem Pendukung Keputusan adalah system tambahan, mampu untuk mendukung analisis data secara ad hoc dan pemodelan keputusan serta berorientasi pada perencanaan masa depan. Dengan demikian, dapat disimpulkan bahwa Sistem Pendukung Keputusan adalah system berbasis model yang terdiri dari prosedur dalam pemrosesan data dan pertimbangannya untuk membantu manajer dalam mengambil keputusan[7]. 


\section{Fuzzy Multiple Attribut Decition Making}

FMADM adalah suatu metode yang digunakan untuk mencari alternative optimal dari sejumlah alternatif dengan kriteria tertentu[8][9][10]. Ada beberapa metode yang dapat digunakan untuk menyelesaikan masalah FMADM. Antara lain[11][12][13]:

a. Simple Additive Weighting Method (SAW)

b. Weighted Product (WP)

c. ELECTRE

d. Technique for Order Preference by Similarity to Ideal Solution (TOPSIS)

e. Analytical Hierarchy Process (AHP)

\section{Metode Penelitian}

\section{A. Tahap Pengumpulan Data}

Untuk mengidentifikasikan permasalahan pada system yang berjalan, penulis menggunakan teknik pengumpulan data sebagai berikut :

a. Observasi yaitu pengkajian terhadap masalah yang diambil dengan cara melihat dan mempelajari langsung terhadap objek penelitian.

b. Interview dimana penulis memperoleh data dan informasi dengan cara Tanya jawab dengan pihak yang bersangkutan dan mempunnyai hubungan dengan permasalahan yang diteliti.

c. Pustaka yaitu penulis mengambil data dari buku-buku dan jurnal-jurnal yang berhubungan dengan objek penelitian[14].

\section{B. Metode Weighted Produck}

Konsep permasalannya adalah mengevaluasi $\mathrm{m}$ alternative $(\mathrm{i}=1,2, \ldots, \mathrm{m})$ terhadap sekumpulan atribut atau criteria $(j=1,2, \ldots, n)$, dimana setiap atribut tidak saling bergantungan satu dengan yang lainnya[15]. Metode WP menggunakan proses normalisasi, dimana rating setiap atribut harus dipangkatkan dahulu dengan bobot atribut yang bersangkutan[16]. Proses ini diberikan dengan rumus sebagai berikut:

$$
S_{i}=\prod_{j=1}^{n} x_{i j}{ }^{w_{j}}
$$

Dengan $\overline{I=1,2, \ldots, \mathrm{m} \text {, dimana: }}$

$\mathrm{S}$ menyatakan preferensi alternatif,

$\mathrm{X}$ menyatakan nilai kriteria,

W menyatakan bobot kriteria,

$\mathrm{N}$ menyatakan banyaknya kriteria.

$W_{J}$ adalah pangkat bernilai positif untuk atribut keuntungan, dan bernilai negatif untuk atribut biaya[17].

\section{Alternatif $\left(A_{i}\right)$}

Alternative $A_{i}$ dengan $i=1,2, \ldots$, m adalah objekobjek yang berbeda dan memiliki kesempatan yang sama untuk dipilih oleh pengambil keputusan. Data yang digunakan adalah data lahan desa yangdiusulkan untuk pengklasifikasian lahan dalam bidang kegiatan sarana prasarana sejumlah 4 desa di Kecamatan Sendang Agung, yaitu: Sendang Agung, Sendang Asri, Sendang Mukti, Sendang Baru. Preferensi relative dari setiap alternative diberikan sebagai:

$$
\mathrm{Vi}=\frac{\prod_{j=1}^{\mathrm{n}} X_{\mathrm{ij}}{ }^{\mathrm{Wj}}}{\prod_{j=1}^{\mathrm{n}}\left(X_{j}^{*}\right) W_{j}}
$$

Dimana:

$\mathrm{V}=$ Perefensi Alternatif

$\mathrm{X}=$ Nilai Kriteria

$\mathrm{W}=$ Bobot

\section{Bobot}

Dalam metode penelitian ini ada bobot dan kriteria yang dibutuhkan untuk menentukan lahan mana yang akan terseleksi dengan ketentuan yang sudah ditentukan. Adapun kriterianya adalah (Wulandari et.al, 2016).[3]:

$\mathrm{C} 1=$ Jenis Lahan

C2 $=$ Tekstur Lahan

C3 = Curah Hujan

$\mathrm{C} 4=$ Suhu

C5 = Lokasi

C6 =Nilai

Dari masing-masing bobot tersebut, maka dibuat suatu variable-variabelnya. Dimana dari suatu variabel tersebut akan dirubah kedalam bilangan fuzzynya.

Dibawah ini adalah bilangan fuzzy dari bobot.

1. Sangat Rendah (SR) $=0$

2. Rendah $(\mathrm{R}) \quad=0.2$

3. Sedang (S) $\quad=0.4$

4. Tengah $(\mathrm{T} 1) \quad=0.6$

5. Tinggi $(\mathrm{T} 2) \quad=0.8$

6.Sangat Tinggi (ST) $=1$

Untuk mendapat variabel tersebut harus dibuat dalam sebuah grafik supaya lebih jelas pada gambar 1 .

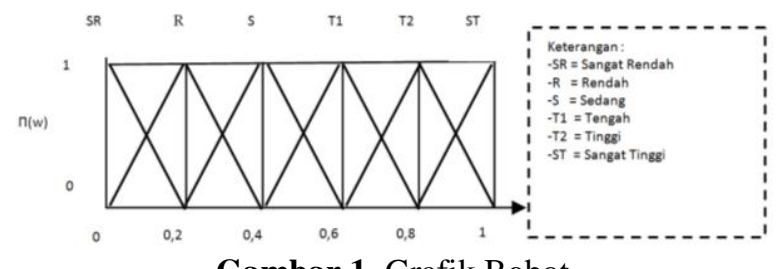

Gambar 1. Grafik Bobot 


\section{E. Kerangka Fikir Penelitian}

Langkah-langkah analisa permasalahan dengan metode Weighted Product digambarkan dalam diagram alir berikut [17] :

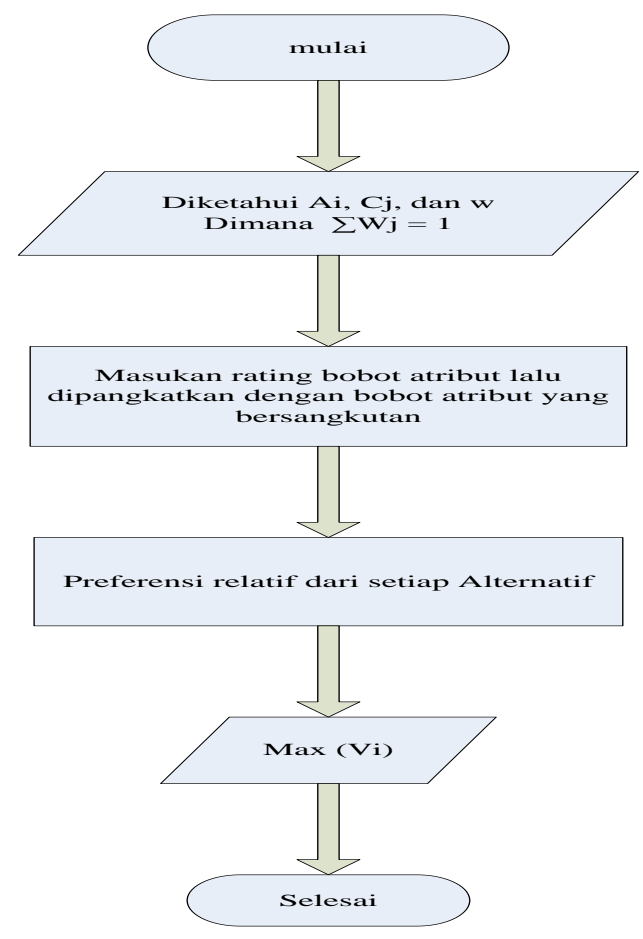

Gambar 2. Diagram Alir Penelitian

\section{Pembahasan}

\section{A. Kriteria dan Bobot Weighted Product}

Untuk menyelesaikan masalah dengan metode weighted product, menentukan kriteria-kriteria yang akan dijadikan acuan dalam pengambilan keputusan yaitu sebagai berikut [18] :

\section{Tabel 1 :Kode dan Ketentuan Kriteria}

\begin{tabular}{|c|l|c|}
\hline $\begin{array}{c}\text { Kode } \\
\text { Kriteria }\end{array}$ & \multicolumn{1}{|c|}{$\begin{array}{c}\text { Ketentuan } \\
\text { Kriteria }\end{array}$} & Nilai Bobot \\
\hline C1 & Jenis Lahan & $18 \%$ \\
\hline C2 & Tekstur Lahan & $22 \%$ \\
\hline C3 & Curah Hujan & $23 \%$ \\
\hline C4 & Suhu & $20 \%$ \\
\hline C5 & Lokasi & $8 \%$ \\
\hline C6 & Nilai & $9 \%$ \\
\hline
\end{tabular}

Tabel 2 :Kriteria Jenis Lahan (C1)

\begin{tabular}{|c|l|c|}
\hline Jenis Tanah & \multicolumn{1}{|c|}{ Bobot } & Nilai \\
\hline Persawahan & Sangat Tinggi & 1 \\
\hline Perkebunan & Tinggi & 0,8 \\
\hline Pegunungan & Sedang & 0,4 \\
\hline
\end{tabular}

Tabel 3 : Kriteria Tekstur Lahan (C2)

\begin{tabular}{|c|l|c|}
\hline Tekstur Tanah & Bobot & Nilai \\
\hline Lembut Dan Basah & Rendah & 0,2 \\
\hline
\end{tabular}

Copyright $\odot 2018$ FIKOM - UNASMAN

http://ejournal.fikom-unasman.ac.id

\begin{tabular}{|l|l|c|}
\hline Liat & Sedang & 0,4 \\
\hline Bembur & Sangat Tinggi & 1 \\
\hline
\end{tabular}

Tabel 4 : Kriteria Curah Hujan (C3)

\begin{tabular}{|l|l|c|}
\hline \multicolumn{1}{|c|}{ Curah Hujan } & \multicolumn{1}{c|}{ Bobot } & Nilai \\
\hline Rendah & Rendah & 0,2 \\
\hline Sedang & Sedang & 0,4 \\
\hline Tinggi & Tinggi & 0,8 \\
\hline Sangat Tinggi & Sangat Tinggi & 1 \\
\hline
\end{tabular}

Tabel 5 : Kriteria Suhu (C4)

\begin{tabular}{|l|l|c|}
\hline \multicolumn{1}{|c|}{ Suhu } & \multicolumn{1}{c|}{ Bobot } & Nilai \\
\hline Dingin & Rendah & 0,2 \\
\hline Normal & Sedang & 0,4 \\
\hline Hangat & Tinggi & 0,8 \\
\hline Panas & Sangat Tinggi & 1 \\
\hline
\end{tabular}

Tabel 6 : Kriteria Lokasi (C5)

\begin{tabular}{|l|c|c|}
\hline \multicolumn{1}{|c|}{ Lokasi } & Bobot & Nilai \\
\hline Tinggi Tempat & Rendah & 0,2 \\
\hline Sinar Matahari & Tengah & 0,6 \\
\hline Sumber Air & Sangat Tinggi & 1 \\
\hline
\end{tabular}

Tabel 7 : Kriteria Nilai (C6)

\begin{tabular}{|l|l|c|}
\hline \multicolumn{1}{|c|}{ Nilai } & \multicolumn{1}{|c|}{ Bobot } & Nilai \\
\hline C6 $<=50$ & Sangat Rendah & 0 \\
\hline $50<$ C6 $<60$ & Rendah & 0,2 \\
\hline $60<$ C6 $<70$ & Sedang & 0,4 \\
\hline $70<$ C6 $<80$ & Tengah & 0,6 \\
\hline $80<$ C6 $<90$ & Tinggi & 0,8 \\
\hline C6 $>=90$ & Sangat Tinggi & 1 \\
\hline
\end{tabular}

\section{B. Menentukan Rating Kecocokan}

Langkah pertama menentukan alternatifnya terlebih dahulu dengan nilai kriteria yang sudah ditentukan, Alternatif yang akan diteliti adalah sebagai berikut :

A1 : Sendang Agung

A2 : Sendang Asri

A3 : Sendang Mukti

A4 : Sendang Baru

Tabel 8 : Alternatif

\begin{tabular}{|c|c|c|c|c|c|c|}
\hline \multirow{2}{*}{ Alternatif } & \multicolumn{7}{|c|}{ Kriteria } \\
\cline { 2 - 7 } & C1 & C2 & C3 & C4 & C5 & C6 \\
\hline A1 & 0,8 & 0,4 & 0,8 & 0,2 & 1 & 0,4 \\
\hline A2 & 0,4 & 0,2 & 0,4 & 1 & 0,6 & 0,6 \\
\hline A3 & 1 & 0,2 & 0,8 & 0,4 & 0,2 & 0,2 \\
\hline A4 & 1 & 1 & 0,2 & 0,4 & 0,6 & 1 \\
\hline
\end{tabular}

Langkah kedua adalah perhitungan metode WP yang dimulai dengan cara menentukan perbaikan bobot dimana nilai $=1$ yaitu: $\mathrm{W}=0,180,220,23$ 0,2 0,08 0,09.(Aziz Ahmadi dan Dian Tri Wiyanti, 2014).[8] 


\section{Menentukan Nilai Vektor $S$}

Langkah Ketiga adalah menentukan nilai vector $\mathrm{S}$. dengan cara mengalikan data setiap nilai alternatif rating kecocokan yang berpangkat positif dari hasil perbaikan bobot. Data perhitungan nilai vektor $\mathrm{S}$ dari setiap alternatif dapat dilihat seperti berikut.

1. Sendang Agung

S1 : $\quad\left(0,8^{0,18}\right) \quad\left(0,4^{0,22}\right) \quad\left(0,8^{0,23}\right) \quad\left(0,2^{0,2}\right)$ $\left(1^{0,08}\right)\left(0,4^{0,09}\right)=0,497864879$

2. Sendang Asri

$$
\begin{aligned}
& \text { S2 : } \quad\left(0,4^{0,18}\right) \quad\left(0,2^{0,22}\right) \quad\left(0,4^{0,23}\right) \quad\left(1^{0,2}\right) \\
& \left(0,6^{0,08}\right)\left(0,6^{0,09}\right)=0,441933484
\end{aligned}
$$

3. Sendang Mukti

$$
\begin{aligned}
& \text { S3 : } \quad\left(1^{0,18}\right) \quad\left(0,2^{0,22}\right) \quad\left(0,8^{0,23}\right) \quad\left(0,4^{0,2}\right) \\
& \left(0,2^{0,08}\right)\left(0,2^{0,09}\right)=0,422205993
\end{aligned}
$$

4. Sendang Baru

S4

$$
:\left(1^{0,18}\right)\left(1^{0,22}\right)\left(0,2^{0,23}\right)\left(0,4^{0,2}\right)\left(0,6^{0,08}\right)\left(1^{0,09}\right)
$$$$
=0,551951601
$$

Langkah keempat adalah hasil dari penentuan nilai vector $\mathrm{S}$ kemudian digunakan untuk menentukan nilai vector $\mathrm{V}$ untuk mendapatkan nilai alternatif tertinggi dari setiap nilai vector $\mathrm{V}$. proses pencarian vektor $\mathrm{V}$ padaNilai vector $\mathrm{V}$ yang digunakan untuk perankingan :

$$
\begin{aligned}
& \text { V1 }: \frac{0,046606444}{1,913955957}=0,260123477 \\
& \text { V2 }: \frac{0,441933484}{1,913955957}=0,23090055 \\
& \text { V3 }: \frac{0,422205993}{1,913955957}=0,220593369 \\
& \text { V4 }: \frac{0,551951601}{1,913955957}=0,288382603
\end{aligned}
$$

Dari hasil tersebut dapat disimpulkan bahwa alternatif pemilihan lahan terbaik di Sendang Agung adalah Desa Sendang Baru dengan V4= 0,288382603 .

\section{Hasil Penelitian}

Hasil pengujian penerapan metode weighted product pada system sudah sesuai dengan perhitungan secara manual. Perhitungan penunjang keputusan menggunakan metode WP pada system menghasilkan alternatif terbaik yaitu pengklaifikasian lahan di Desa Sendang Agung, dengan nilai V4 = 0,288382603 terbesar pada alternatif Desa Sendang Baru.

\section{E. Uji Sistem Aplikasi}

Aplikasi system pendukung keputusan pengklasifikasian lahan di Desa Sendang Agung dengan menggunakan Microsoft Excel antara lain sebagai berikut :

\begin{tabular}{|c|c|c|}
\hline \multicolumn{2}{|c|}{ Vektor V (Hasil Akhir) } & Ranking \\
\hline V1 & 0.260123477 & 2 \\
\hline V2 & 0.23090055 & 3 \\
\hline V3 & 0.220593369 & 4 \\
\hline V4 & 0.288382603 & 1 \\
\hline
\end{tabular}

Tabel 9. Hasil Akhir dan Perangkingan

Tabel 9 merupakan hasil akhir dari nilai vector $\mathrm{V}$ dimana rangking 1 terdapat pada nilai terbesar pada alternative ke4 dengan nilai 0.288382603 pada Desa Sendang Baru.

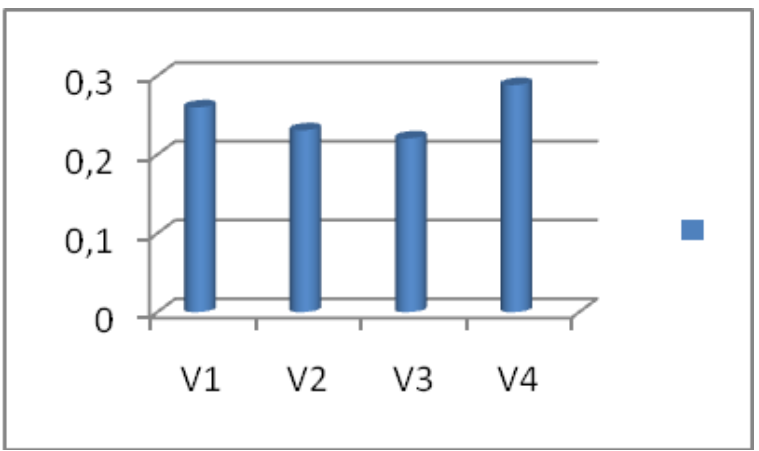

Gambar 6. Grafik Hasil Akhir

Gambar 6 adalah grafik nilai akhir merupakan hasil dari perangkingan dari setiap alternative dimana rangking 1 terdapat pada alternative ke4, rangking 2 terdapat pada alternative ke1, rangking 3 terdapat pada alternative ke2, dan rangking 4 terdapat pada alternative ke3.

\section{KESIMPULAN}

Dari hasil pembahasan permasalahan diatas dapat diambil kesimpulan bahwa pengambilan keputusan untuk pengklasifikasian lahan menggunakan metode Weighted Product dengan menggunakan kriteria jenis lahan, tekstur lahan, curah hujan, suhu, lokasi dan nilai. Berdasarkan empat alternatif yang di uji yang mewakili 4 desa di kecamatan Sendang Agung diperoleh hasil Desa Sendang Agung V1 = 0,260123477, Desa Sendang Asri V2 = 0,23090055, Desa Sendang Mukti V3 = 0,220593369, Desa Sendang Baru V4 = 0,288382603, nilai terbesar dari penjumlahan matriks di atas adalah V4 = 0,288382603, dengan demikian alternative V4 dapat disebut mempunnyai lahan terbaik dengan alternatif Desa Sendang Baru.

\section{REFERENSI}

[1] M. L. R. Ayyu Rahayu, Sri Rahayu Utami, 
"Characteristics And Classification Of Land On Dry And Land Derivatives In The Subsidiary District Of Jombang District," J. tanah dan sumber daya lahan, vol. 1, no. 2, pp. 1-9, 2014.

[2] E. S. M. Jaka Suyana, "Analysis Of Land Ability Of Agricultural System In Sub-Das Of Regions Of Capture Distances Of Kedung Ombo," J. ilmu tanah dan agroklimatolo, vol. 11, no. 2, pp. 1-11, 2014.

[3] F. A. F. Wulandari, Ahmad Mustofa, Ponidi, Muhamad Muslihudin, "Decision Support System of Agricultural Land Mapping Qualified To Improve Rice Production Using Simple Additive Weighting Method (SAW)," SEMNASTEKNOMEDIA, vol. 4, no. 1, pp. 1-6, 2016.

[4] D. Djaenudin, "Research Development Of Land Resources And Contributions To Overcome The Need For Agricultural Lands In Indonesia," J. Litbang Pertan., vol. 27, no. 98, pp. 137-145, 2008.

[5] I Gede Budiarta, "Evaluation Of Land Use Adjustment As Effort Increasing Regional Quality Of River Flow," $J$. media Komun. Geogr., vol. 17, no. 1, pp. 1-10, 2016.

[6] K. A. Henry Wibowo, Riska Amalia, Andi Fadlun M, "Sistem Pendukung Keputusan Untuk Menentukan Penerima Beasiswa Bank BRI Menggunakan FMADM (Studi Kasus: Mahasiswa Fakultas Teknologi Industri Universitas Islam Indonesia)," Semin. Nas. Apl. Teknol. Inf. 2009, no. Snati, pp. 1-6, 2009.

[7] R. H. Amelia Yusnita, "Sistem Pendukung Keputusan Menentukan Lokasi Rumah Makan Yang Strategis Menggunakan Metode Naive Bayes," Semin. Nas. Teknol. Inf. dan Komun. Terap. 2012, vol. 2012, no. Semantik, pp. 1-5, 2012.

[8] A. D. Susanti, M. Muslihudin, and S. Hartati, "Sistem Pendukung Keputusan Perankingan Calon Siswa Baru Jalur Undangan Menggunakan Simple Additive Weighting ( Studi Kasus: SMK Bumi Nusantara Wonosobo )," SEMNASTEKNOMEDIA, vol. 5, no. 1, pp. 37-42, 2017.

[9] F. S. Nur Aminudin, Nungsiyati, Khuswatun Hasanah, Andino Maseleno, "Fuzzy Multiple Attribute Decision Making Sebagai Metode Penentuan Pemukiman Kumuh Di Wilayah Pringsewu," J. TAM ( Technol. Accept. Model ), vol. 8, no. 2, pp. 136-145, 2017.

[10] M. Muslihudin, D. Kurniawan, and I. Widyaningrum, "Implementasi Model Fuzzy SAW Dalam Penilaian Kinerja Penyuluh Agama," J. TAM ( Technol. Accept. Model ), vol. 8, no. 1, pp. 39-44, 2017.

[11] S. W. Satria Abadi, "The Model of Determining Quality of Management Private Higher Education Using FAHP (Fuzzy Analytic Hierarchy Process) Method," in ICESIA 1, 2016, vol. 1, no. 1, pp. 166-172.

[12] M. Muslihudin and M. Gumanti, "A System To Support Decision Makings In Selection Of Aid Receivers For Classroom Rehabilitation For Senior High Schools By Education Office Of Pringsewu District By," IJISCS, vol. 1, no. 2, pp. 1-9, 2017.

[13] M. Muslihudin, F. Triananingsih, and L. Anggraei, "Pembuatan Model Penilaian Indeks Kinerja Dosen Menggunakan Metode Fuzzy Simple Additive Weighting," SEMNASTEKNOMEDIA, vol. 5, no. 1, pp. 25-30, 2017.

[14] M. M. Riyan Suhandi, Leni Anggraeni, "Cara Penentuan Kelayakan Calon Kepala Desa Pada Desa Blitarejo Menggunakan Metode Simple Additive Weighting (SAW)," Konf. Nas. Sist. Inf., vol. 0, no. 0, pp. 65-73, 2016.

[15] S. Mukodimah, M. Muslihudin, and A. Maseleno, "Implementasi Weighted Product Untuk Mengukur Indeks Kinerja Kepala Desa Di Kecamatan Pringsewu,' KNSI, pp. 23-40, 2018.

[16] K. Slamet Hidayat, Rita Irviani, "Sistem Pendukung Keputusan Pemilihan Guru Teladan Ma Al Mubarok Batu Raja Menggunakan Metode Topsis," J. TAM ( Technol. Accept. Model ), vol. 6, no. 1, pp. 1-8, 2016.

[17] D. T. W. Aziz Ahmadi, "Implementasi Weighted Product ( WP ) Dalam Penentuan Penerima Bantuan Langsung Masyarakat Pnpm Mandiri Perdesaan," Semin. Nas. Apl.

Copyright (C) 2018 FIKOM - UNASMAN

http://ejournal.fikom-unasman.ac.id
Teknol. Inf., vol. 0, no. 0, pp. 1-4, 2014

[18] I. F. A. Septiyana Firdyana, Dedy Cahyadi, "Penerapan Metode Weighted Product Untuk Menentukan Penerima Bantuan Beras Masyarakat Miskin ( RASKIN )," Pros. Semin. ilmu Komput. dan Teknol. Inf., vol. 2, no. 1, pp. 1-7, 2017. 